important recommendation in the report is no doubt the call for a 'world weather watch', a global meteorological observing and prediction system designed to avoid duplication of effort in the preparation of analysed charts and forecasts, yet providing all meteorological services with the basic data needed to carry out their responsibilities. The report also proposes that the scope and quality of both conventional and satellite observations should be improved and emphasizes that the latter supplement but do not supplant the former. Optimum results can be achieved by means of a combination of the wide scanning ability of the satellites with the capabilities of the usual vertical sounding instruments. Improvements should also be made to the communication facilities to permit the rapid trans- mission of a greatly increased volume of meteorological traffic throughout the world. The hope is expressed that the satellites themselves may serve as communication systems for this purpose.

The evaluation of the optimum utilization of meteorological satellites is an important issue that must be faced. The United Nations and its specialized agency, the World Meteorological Organization, have taken a big step forward. The working group which has been established to formulate an atmospheric sciences programme will keep the matter under active review until the World Meteorological Organization Congress constitutes an advisory committee at its fourth session in April 1963. There is a long road to tread before the full potential of meteorological satellites will come to fruition. A. H. GorDON

\title{
FILARIASIS
}

$\mathrm{D}$ URING the past few years, filariasis control has progressed to the point where it has become possible to look forward to the introduction of eradication campaigns like that organized by the World Health Organization for malaria. In contrast to the malaria programmes, however, the first line of attack would have to be mass chemotherapy, mainly because of the long life of the parasite in the human body. To keep transmission at a low enough level to ensure eradication, chemotherapy will have to be backed up by adequate vector control. This may not prove easy, since the culicine mosquitoes, the main vectors of filariasis, rapidly acquire resist. ance to the commonly used insecticides and since the habitats of some of the mosquitoes make it difficult to attack them by conventional methods.

The World Health Organization Expert Committeo on Filariasis has reviewed recent advances in the epidemiology of Wuchereria and Brugia infections and directed attention to the many problems on which research is still needed*. It is important to improve methods of identifying developing forms of filariæ in mosquitoes, so that carriers of animal filariæ should not be mistaken for vectors of the

* World Health Organization. Technical Report Series. No. 233 : Expert Committee on Filariasis (Wuchereria and Brugia Infections) H.M. Stationery Office, 1962). 2 Swiss franes ; $3 s .6 d . ; 0.60$ dollars. human infection. Expert taxonomic, $\theta$ cological and other studies are needed to establish the strains with the highest infective potential and the most effective means of destroying them. Rapid urbanization has enabled Culex fatigans to breed apace in some areas with only primitive sanitation, and the situation has been made worse where insecticide spraying campaigns for malaria eradication have eliminated competitors of this mosquito. The Committee recommends that, wherever possible, Culex fatigans should be attacked by improvements in sanitation aimed at suppressing man-made breeding sites.

Diethylcarbamazine appears to be still the most satisfactory drug available for mass chomotherapy, but a number of new compounds containing arsenic or antimony are at present under trial. Further research is needed to establish the best dosage schedule for diethylcarbamazine- one that, in order to ensure a high acceptability, combines effectiveness with ease of administration and relative freedom from side-effects.

Among the other subjects suggested for research. the Committee advocates studies on transmission and on the life-cycle of the parasite in relation to clinical manifestations, serological and immunological studies on filariasis, and an investigation of the effect of malaria eradication activities on the local epidemiology of filariasis.

\section{INHERITANCE IN BACTERIA}

\begin{abstract}
MONG the wide variety of research activities described in the report of the Governing Body of the Lister Institute of Preventive Medicine for $1962 *$, that of the investigations of the GuinessLister Unit into inheritance in bacteria is of particular interest. The Unit continued its investigation of inheritance in bacteria of the Salmonella (food poisoning and enteric fever) groups, using two different kinds of fertility factor to induce conjugation: the colicine factors, which determine the production of antibiotics called colicines, and the $F$ factor and some variants of it, transferred from Escherichia coli.
\end{abstract}

* The Lister Institute of Preventive Medicine. Report of the Governing Body 1962. Pp. 29. (London: The Lister Institute of Preventive Medicine, 1962).
S. Smith continued to map the chromosome of Salmonella typhimurium, obtaining conjugation (and hybridization) by the use of colicine factors col $I$ and col EI. Additional hereditary characters were introduced into the strains used, by the isolation of mutants unable to synthesize particular amino-acids, to ferment particular sugars or to produce the fraction of the polysaccharide component of the $O$ antigen factor 5. Many of these mutants were obtained by treating bacteria with the mutagen ethyl methane sulphonate. The genes regulating all the characters concerned were mapped in the single closed-loop linkage map already tentatively established. Dr. B. A. D. Stocker, E. Subbaiah, and E. Dubnau, using the same system, investigated the segregation of additional characters resulting from 